Recepción: 20 / 01 / 2019

Aceptación: 19 / 03 / 2019

Publicación: 05 / 05 / 2019

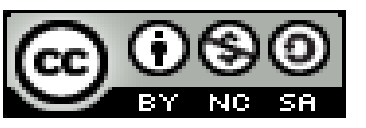

Ciencias de la salud

Artículo de Revisión

\title{
Aspectos fisiopatológicos en pacientes con problemas de tiroides
}

\section{Pathophysiological aspects in patients with thyroid problems}

\section{Aspectos fisiopatológicos em pacientes com problemas de tireóide}

\author{
Marcos A. Bedoya-Romo ${ }^{\mathrm{I}}$ \\ marcos4786@hotmail.es \\ Pierina E. Saltos-Montes II \\ pierina_s.m@hotmail.com \\ Marcos A. Campozano-Burgos III \\ andres_bigman25@hotmail.com \\ Eduardo I. Ayala-Morillo IV \\ eduyala11@hotmail.com \\ Evelyn E. Calderón-López ${ }^{\mathrm{V}}$ \\ ivitef89@gmail.com \\ Marvin D. Veliz-Mero VI \\ drmarveliz@hotmail.com
}

Correspondencia: marcos4786@hotmail.es

Médico Cirujano; Médico Residente de UCI del Hospital General IESS; Manta, Ecuador Médico Cirujano; Médico Residente de Emergencia del Hospital General IESS; Manta, Ecuador Médico Cirujano; Médico Residente de UCI del Hospital General IESS; Manta, Ecuador Médico Cirujano; Médico Residente de UCI del Hospital General IESS; Manta, Ecuador Médico Cirujano; Médico Residente de Neonatología del Hospital General IESS; Manta, Ecuador Médico Cirujano; Médico Residente de Cirugía del Hospital General IESS; Manta, Ecuador. 


\title{
Resumen
}

La estructura fisiológica de los órganos que estructuran a los seres humanos, cumplen un papel importante para la vida y salud integral de los niños, niñas, adolescentes, jóvenes, adultos y ancianos. Dentro de este grupo, la tiroides como glándula endocrina ubicada por debajo de la nuez de Adán junto al cartílago tiroides sobre la tráquea, la cual pesa entre 15 a 30 gramos en el adulto; además, posee dos lóbulos en forma de mariposa a ambos lados de la tráquea en el cuello. Es importante acotar que, entre sus principales funciones se encuentra regular las hormonas y sensibilidad de otras hormonas. Sin embargo, cuando existe una alimentación deficitaria en las necesidades diarias de yodo establecidas en $200 \mathrm{mcg}$, se presenta que su funcionamiento puede ubicarse en un incremento o reducción de la tiroxina $\left(\mathrm{T}_{4}\right)$ y la triyodotiromina $\left(\mathrm{T}_{3}\right)$. Situación que conlleva a la aparición de diferentes patologías como: hipertiroidismo, hipotiroidismo, bocio, nódulos tiroideos y cáncer. Según la Organización Mundial de la Salud (2016) señala que "el 40\% de la población está en riesgo de presentar deficiencia de yodo". (p.7). Esto lleva a entender el significado que presenta para los individuos vigilar el consumo de la sal yodada, pues, de su gesta puede llegar a tener un adecuado e inadecuado funcionamiento y en esa dirección aparecen las diferentes enfermedades tiroideas que van a afectar a los individuos en la realización de sus actividades diarias al ocasionar: depresión, insomnio, obesidad, dolores articulares, infertilidad, enfermedades coronarias entre otros. Aspectos considerados como un aporte significativo para el desarrollo de este artículo, mediante el cual se busca llegar a un análisis referido a los aspectos fisiopatológicos en pacientes con problemas de tiroides, el mismo responde al tipo documental apoyado en fuentes reflexivas que apoyan la lectura crítica para finalmente llegar a construir un grupo de conclusiones.

Palabras claves: Aspectos Fisiopatológicos; Paciente; Problemas de Tiroides.

\begin{abstract}
The physiological structure of the organs that structure to human beings, fulfilled an important role in the life and health of children, girls, adolescents, young people, adults and elders. Within this group, the thyroid as endocrine gland located below the Adam's Apple with the thyroid cartilage on the trachea, which weighs between 15 to 30 grams in the adult; In addition, it has two lobes in Butterfly shape on both sides of the trachea in the neck. It is important to note that, among its main
\end{abstract}


functions is regulate hormones and sensitivity of other hormones. However, when there is a daily iodine needs established in $200 \mathrm{mcg}$ deficient diet, is that its operation can be located in an increase or decrease of the triyodotiromina (T3) and thyroxine (T4). Situation that leads to the emergence of different pathologies such as: hyperthyroidism, hypothyroidism, goiter, thyroid nodules and cancer. According to the World Health Organization (2016), he says that "40\% of the population is at risk for iodine deficiency". (p.7). This leads to understand the meaning presenting for individuals to monitor the consumption of iodized salt, because of his feat you can have proper and improper operation and in that direction are different thyroid diseases that go to individuals in their daily activities affect the result: depression, insomnia, obesity, joint pain, infertility, heart disease among others. Aspects regarded as a significant contribution to the development of this article, which seeks to reach a referred to the physiopathological aspects analysis in patients with thyroid problems, it responds to the supported document type in reflective sources that support the critical reading to finally get to build a group of.

Keys words: Physiopathological aspects; Patient; Thyroid problems.

\section{Resumo.}

A importância de cuidar da audição depende de cada indivíduo, o trabalho de pesquisa a seguir estuda os mecanismos de prevenção que devem ser considerados para reduzir os problemas causados ao ouvido pela exposição ao ruído, através de uma revisão bibliográfica que enfoca questões relacionadas ao interesse e que forneceu contribuições para a investigação. $\mathrm{O}$ trabalho faz menção ao ouvido como um dos órgãos mais importantes do ser humano e a perda auditiva que ocorre de acordo com determinados ambientes de trabalho que produzem ruídos perigosos e que podem gerar o que se conhece como perda auditiva induzida, considerando que este tipo de problema pode ser evitado se medidas de proteção forem tomadas e se os controles e estudos de pesquisa necessários nas empresas forem mantidos para cuidar da audiência de cada um de seus trabalhadores e evitar prejuízos que mais tarde poderiam ser irreversíveis. Durante a investigação observa-se como os trabalhadores que estão expostos a riscos de ruído há anos perdem a capacidade de ouvir o porquê, mencionam-se os Programas de Prevenção Auditiva do Instituto de Segurança e Saúde Ocupacional (NIOSH) responsáveis pela realização das avaliações apropriadas. e controles, a fim de garantir a audição de seus funcionários. Os mecanismos de prevenção devem ser uma 
prioridade para cada empresa e para cada indivíduo, é para o funcionário cuidar de si e usar o equipamento de proteção sem ter que receber chamadas de atenção para o seu uso pelo pessoal de segurança da empresa, bem como como, a empresa deve garantir um check-up médico para todos aqueles que trabalham em ambientes perigosos.

Palavras chaves: Aspectos fisiopatológicos; Paciente Problemas de tireóide.

\section{Introducción.}

Al hacer referencia a la tiroides, se precisa que es una glándula caracterizada por una estructura firme, lisa de color marrón rojizo, además presenta dos lóbulos laterales que se conectan entre sí mismo. Asimismo, se puede resaltar que con respecto a los demás órganos es el más vacularizado y presenta una de las tasas más elevadas del flujo sanguíneo. De allí la importancia que poseen las hormonas tiroideas, pues, las mismas son determinantes para el desarrollo mental como somático del niño y en la actividad metabólica del adulto.

Cabe destacar que, existen dos tipos de hormonas tiroideas activas biológicamente: la tiroxina $\left(\mathrm{T}_{4}\right)$, quecorresponde al 93\% de hormona secretada por la glándula tiroides, y triyodotironina $\left(\mathrm{T}_{3}\right)$. Ambas están compuestas por dos anillos bencénicos unidos por un puente de oxígeno, uno de los cuales tiene una cadena de alanina y otro un grupo fenilo. La diferencia entre ambashormonas es que mientras $\mathrm{T}_{4}$ tiene 2 átomos de yodo en el anillo del grupo fenilo, la $\mathrm{T}_{3}$ tiene sólo uno. También hay otra forma denominada rT3 triyodotironina inversa) que noposee actividad biológica.

De las evidencias anteriores, se puede decir que para formar una cantidad normal de tiroxina se precisan al año unos $50 \mathrm{mg}$ de yodo (ingerido en forma de yoduros), o sea, unos 150mg/día en adultos; en cambio las embarazadas deben consumir unos $220 \mathrm{mg} /$ día, y en niños varía con la edad. Cuando las cantidadesingeridas son crónicamente inferiores aparece bocio (aumento del tamaño de la glándula), esto también ocurre alingerir sustancias que interfieren en la absorción gastrointestinal del yodo obien en su utilización por la glándula denominadas bociógenos. Para evitar el déficit de yodo seha añadido yoduro sódico a la sal común. Pues los yoduros ingeridos por vía oral se absorben desde el tubo digestivo hasta la sangre y su mayoría son excretados por vía renal, pero, en condiciones normales, 1/5 parte es retirada por lascélulas tiroideas para la síntesis de las hormonas tiroideas. 
Por ello, para medir el déficit de yodo se puedehacer mediante la excreción urinaria del mismo, así, a menor excreción, mayor déficit. Por otra parte, y en sentido inverso, también las hormonas tiroideas son metabolizadashasta yoduros en diversos tejidos diana de las mismas. Este yoduro pasa a sangre y escaptado por la glándula tiroides o excretado por orina. Existe una pequeña cantidad de yodo (unos 10-20mg) que se pierde por las heces.Cuando la ingesta de yodo es inferior a los requerimientos aumenta la proporción que escaptada y utilizada en la tiroides frente a la que se elimina por la orina, al ser superior a los requerimientos se elimina una proporción mayor por la orina.

Al respecto, Hernández y Rendón (2015) precisa que para lograr una combinación básica de las hormonas tiroideas debe haber:

T4: el 75\% está unido a TBG, el 10\% a TTR, el 12\% a albúmina y el 3\% a lipoproteínas. Aproximadamente el $0.02 \%$ está libre en suero. T3: el 80\% está unido a TBG, el 5\% a TTR y el $15 \%$ a albúmina y lipoproteínas. Aproximadamente el $0.5 \%$ está libre en suero. (p.6)

Al vincular estas evidencias con los planteamientos del artículo, se precisa que para lograr la concentración de $\mathrm{T}_{4}$ y $\mathrm{T}_{3}$ libres, presentes para poder determinar la actividad biológica de estas hormonas y está controlada de manera muy precisa. Dado que, al existir un aumento en laconcentración de proteínas de unión en el plasma, la concentración de hormonas libresdisminuye. Este descenso estimula la secreción de TSH hipofisaria que, a su vez incrementa laproducción de hormonas libres, además contribuye a la aparición de las diferentes patologías que son diagnosticadas por los endocrinólogos para así, iniciar el respectivo tratamiento basado en yoduros que estarán estimados en función a la concentración presente en la glándula tiroidea.

En consecuencia, cuando los pacientes son diagnosticados con cualquiera de las patologías que se presentan en dicha glándula, esto conduce a manifestar diferentes eventos fisiopatológicos los cuales, van a estar directamente vinculados con el tipo de enfermedad que ha sido diagnosticada por el endocrino. Para Salazar (2016) "la disfunción tiroidea constituye una de las patologías más prevalecientes en todas las épocas de la vida". (p.21). Por lo tanto, los pacientes que presentan algunas de sus patologías van a tener ciertas manifestaciones a nivel hepático al aumentar el turmoverde ácidos grados, mientras que en los músculos aumenta el metabolismo oxidativo y la 
sensibilidad a la insulina, de igual manera, se observa síntesis de sustancias vaso dilatorias que reducen la resistencia arterial y aumenta el tono venoso entre otras manifestaciones.

Asimismo, Salazar (ob.cit) plantea que "las enfermedades tiroideas no son excepcionales en las mujeres en edad reproductiva, la disfunción tiroidea materna puede repercutir en la salud de la madre en la evolución de la gestación y desarrollo físico y neurológico del neonato”. (p. 32). Es decir, la fisiopatología de las enfermedades correspondientes a la tiroides, van a estar estimada en función al tipo que presenta el paciente, las mismas no son excepcionales en las mujeres embarazadas, su patología requiere de una evaluación acompañada por diferentes especialistas como, endocrino, ginecólogo e internista, con el fin de garantizarle al neonato su respectivo nacimiento en condiciones viables para un desarrollo sano posterior, además de proteger a la madre.

Cabe agregar que la patología relacionada con el hipotiroidismo es vista por Salazar (ob.cit) como "una variable que aumenta con la edad y oscila entre el $4 \%$ y $10 \%$ en la población general, y entre un $45 \%$ y $26 \%$ en ancianos. En niños y adolescentes su prevalencia oscila entre el 1,7\% y el 2,4\%" (p.41). Estas evidencias, permiten valorar que los aspectos físicos - patológicos presente en pacientes con la enfermedad de hipotiroidismo, su prevalencia aumenta de acuerdo a la edad, por lo cual, se hace evidente la presencia de la isquemia cardiaca, además, existen manifestaciones de obesidad, nerviosismo, pérdida del cabello, resequedad de la piel entre otros aspectos físicos patológicos.

En esta misma dirección, Barrientos (2019) destaca que para el año 2019 los cálculos contra el cáncer de tiroides en Estados Unidos puede estar en: "se diagnosticarán alrededor de 52,070 nuevos casos de cáncer de tiroides (14,260 en hombres y 37,810 en mujeres) Alrededor de 2,170 personas morirán a causa de cáncer de tiroides (1,020 hombres y 1,150 mujeres”.(p.14). Según los datos, se puede entender que, para este año en curso, el crecimiento del cáncer de tiroides debe ser tratado con urgencia, pues, los casos crecerán y con ello la mortalidad.

Asimismo, el Instituto Ecuatoriano de Estadísticas y Censos (INEC 2017), indica que el carcinoma de tiroides afecta a: 
54.809 personas en el país, de las cuales el 67.1 por ciento (36.804) son mujeres, este es el segundo cáncer que más afecta, pero además es el más común de tipo diferenciado que afecta a 9 de cada 10 pacientes con esta enfermedad. (p.6)

Estos datos porcentuales, permiten destacar que la presencia del cáncer de tiroides como patología de la respectiva glándula, amerita ser atendido, pues, se incrementan su crecimiento a nivel poblacional. De acuerdo con las ideas descritas anteriormente, se puede indicar que dependiendo de la enfermedad diagnosticada en la glándula tiroidea, pueden encontrarse una gama de aspectos fisiopatológicos, cuando, el paciente tiene la presencia de dos enfermedades tiroideas, la complejidad de dichos aspectos se hace cada vez mayor para los especialistas.

Dado que, el sistema endocrino reflejado en el funcionamiento que tiene la tiroides donde se realizan varios procesos entre la síntesis de las hormonas, su liberación y efecto final en las células blanco. En consecuencia, entre los aspectos fisiopatológicos más comunes son aquellas mutaciones enel receptor de la hormona estimulante de la tiroides o de la proteína $\mathrm{G}$, a las que está asociado, pueden condicionar hiper o hipofuncióndebido a que se han identificado mutaciones quepueden dar actividad o inactividad constitutivadel propio receptor.

De este modo, se puede decir que el aporte inadecuado deyodo o selenio se traduce en función glandularinadecuada o predispone al organismo aciertos trastornos clínicos. Asimismo, y aunqueafortunadamente sólo se ha identificado unamutación en uno de los transportadores de lahormona tiroidea (MTC-8) como la causa deun síndrome devastador de déficit psicomotorsevero, también se ha reconocido resistenciahormonal por mutaciones en los receptoresnucleares de las hormonas tiroideas. En este sentido, Ortega (2016) indica que "cuando un individuo tiene reservas de yodo adecuado solo se absorbe $10 \%$ del yodo requerido que tiene una vida media plasmática de 10 horas aproximadamente, $90 \%$ del yodo se eliminará por la orina".(p.58). Es decir, que el consumo mayor de yodo no será absorbido por el cuerpo, el mismo busca mediante la emisión de orina su salida, para así mantener un equilibrio, pero cuando se produce una deficiencia el dato clínico es el bocio.

En relación con las implicaciones que presentan la presencia de los diferentes aspectos fisiopatológicos en pacientes con problemas de tiroides, se muestra claramente que los mismos están estrechamente vinculados con el tipo de enfermedad que el paciente presente, sólo mediante un 
diagnóstico claro, preciso y coherente, bajo el trabajo disciplinario de diferentes corrientes médicas, se podrá facilitar el desarrollo de los individuos en un contexto particularmente ajustado a sus condiciones orgánicas; pues, dicha glándula por controlar michas de las actividades del cuerpo humano, se van a manifestar velocidad en la quema de calorías, aumento en los latidos del corazón, cansancio, activación, subir y bajar de peso, las mujeres son las más propensas a padecer la enfermedad en comparación con los hombres, especialmente después de un embarazo o luego de la menopausia. Cabe agregar que durante la adolescencia, se expresan cambios en el aspecto físico, como: acné, aumento del grosor del bello, crecimiento exagerado de las mamas, incremento de sensibilidad al cambio de temperatura ambiental, entre otros aspectos.

Cada una de las consideraciones anteriores, sirven para darle continuidad al contenido teórico del artículo, además facilita las condiciones para seleccionar oportunamente el método, tipo de investigación, técnicas y el análisis correspondiente a los eventos caracterizadores del tema para así dar su estructuración básica y poder analizar los aspectos fisiopatológicos en pacientes con problemas de tiroides.

\section{Método.}

Los aspectos que constituyen las palabras claves del artículo, llevan a destacar la respectiva selección de un método, mediante el cual, se buscará el análisis correspondiente al contenido de forma funcional y crítica como una forma práctica para lograr el avance requerido en su proceso investigativo. Por lo tanto, para darle flexibilidad a los diferentes eventos que estructuran al tema, es importante darle correspondencia con lo citado por Barrero (2018) quien expresa "un método le ayuda a cualquier escritor a elaborar consideraciones generales para llegar a indicar en forma clara sus ideas". (p.36)

De acuerdo con lo citado, por el autor se puede indicar que para dar la respectiva acción científica al artículo se procede a seleccionar el método de diferencias que según Barrero (ob.cit) su procedimiento consiste en "reunir varios casos en los que se observen eventos que producen un efecto para luego explicarlo en forma general".(p.43). Lo citado, lleva a entender que mediante dicha aplicación del método diferencias, se puede fijar posiciones claras ante los diferentes aspectos que están directamente relacionados con la fisiopatología en pacientes con problemas de tiroides a 
Marcos A. Bedoya-Romo; Pierina E. Saltos-Montes; Marcos A. Campozano-Burgos; Eduardo I. Ayala-Morillo; Evelyn E. Calderón-López; Marvin D. Veliz-Mero

fin de concluir mediante argumentos básicos la significación que poseen en los individuos que son diagnosticados con cualquiera enfermedad ocasionada por la glándula tiroides.

\section{Tipo de Investigación}

Al buscar desarrollar los eventos que caracterizan el marco metodológico en una investigación, se hace necesario partir de la identificación del tipo, en cuanto al estudio que se lleva a cabo, se encuentra determinado por la definición dada por Carrero (2017), en cuanto al tipo documental "se ocupa del estudio de problemas planteados a nivel teórico, la información requerida para abordarlos se encuentra básicamente en materiales impresos, audiovisuales y /o electrónicos” (p.41).

En razón de esta definición, se puede indicar que al fin de cumplir con las características previas que identifican al trabajo, se realizaron una serie de actividades concernientes a la revisión de fuentes primarias referidas a los aspectos fisiopatológicos en pacientes con problemas de tiroides, para luego ajustar su selección correspondiente a las necesidades de investigación. Para ello, implementó las condiciones que determinan su nivel descriptivo, que según Carrero (ob.cit), "es apreciar, desglosar e indicar en forma analítica todos los hechos de un problema" (p.55).

\section{Técnicas Documentales}

Con el fin de ajustar las diferentes apreciaciones dentro de un orden, coherencia y pertinente, es importante buscar mecanismos idóneos que aseguren la continuidad del proceso investigativo, por ello, es relevante incluir las técnicas documentales como apoyo bibliográfico encargado de dar la respectiva flexibilidad al contenido. Carrero (ob.cit), consiste "en interpretar en forma analítica el contenido de un texto para exponer ideas coherentes y vinculantes entre sí' (p.54).

De igual manera, se puede indicar que mediante la utilización de las técnicas documentales sirvió para la confrontación de las ideas, que hicieron posible tomar hechos generales para separarlos en parte y conformar sus propias apreciaciones individuales. Es decir, se desarrollaron los contenidos en forma generales para luego conformar una estructura global de los hechos a tratar. 
Técnicas de Recolección de Información

La continuidad de las actividades metodológicas llevan a la realización de un conjunto de tareas previas para indicar finalmente ubicar el contenido dentro de una acción interpretativa, es por ello, que se seleccionan técnicas basadas en la lectura como elemento esencial para dar la respectiva organización de las informaciones desde una perspectiva general para llegar a lo particular y retroceder en el otro sentido para conocer las realidades en su totalidad. De allí, que se procedió a identificar los elementos generales que caracterizan el tema una vez interpretado fueron compaginados en forma adecuada hasta responder a cada de las situaciones encontradas en su desarrollo.

Sin embargo, el trabajo del método al ser acompañado por una técnica, como el subrayado y fichaje como alternativas para la revisión y selección final de los aspectos de interés, a criterio de Salazar (ob.cit) "son acciones combinadas para ayudar al investigador a detectar los materiales y adecuarlos a sus propios intereses" (p.78). Una vez cumplida las etapas anteriores se realizaron un conjunto fases todas interconectadas para responder efectivamente a los planteamientos generales.

Por lo tanto, se estimaron las condiciones generales que guardan relación con el tema en estudio, para luego apreciar desde la revisión de aquellos recursos materiales, libros, revistas, periódicos y recursos tecnológicos los eventos contentivos a los aspectos a investigar. Para así, llevar a construir en forma clara los aportes generales que caracterizan una situación o contenido viable para ser estudiado y proporcionar una visión de las apreciaciones particulares que dan cabida a interpretaciones generales para así llegar a construir las conclusiones.

En consecuencia, para ampliar los aspectos generales que fueron estimados con anticipación como interés del presente artículo, se llega al desarrollo de los resultados encargados de proporcionar las respectivas orientaciones que caracterizan a los aspectos fisiopatológico en pacientes con problemas de tiroides. Es decir, una vez cumplida la revisión, selección y preparación del material a insertar en el contenido del artículo investigación, se procedió a la elaboración y desarrollo de los diferentes elementos funcionales que caracterizan al tema con ello, se pudo darle al estudio el respectivo cuerpo interpretativo necesario para su valoración científica. 


\section{Resultados.}

El estudio de los aspectos fisiopatológicos en pacientes con problemas de tiroides, se desglosan en función a las características generales que presenta la respectiva glándula, que representa en la estructura fisiológica del cuerpo humano uno de los órganos más grande, ubicada en la parte inferior del cuello sobre los aspectos anteriores y laterales de la tráquea. Según lo planteado, se presentan a continuación diferentes eventos que dan cabida a la respectiva dirección de los resultados.

\section{Fisiología de la Tiroides}

La glándula tiroides es la primera glándula endocrina que aparece durante el desarrollo embrionario, puede identificarse a los 16-17 días de gestación. Comienza a secretar hormona tiroidea a las 20-24 semanas. Al nacimiento pesa 1-3 g y en el adulto pesa alrededor de $20 \mathrm{~g}$. Se compone de dos lóbulos que se sitúan a ambos lados de la parte superior de la tráquea, unidos por un istmo, que a veces presenta un lóbulo piramidal. Como característica especial, al igual que los testículos, puede explorarse por palpación. Es una de las glándulas endocrinas más grandes y única que posee la capacidad de almacenar grandes cantidades de hormona en un sitio extracelular dentro de un material proteináceo, que se llama coloide tiroideo. Las hormonas tiroideas son las únicas que requieren de un oligoelemento, el yodo, para su síntesis.

Cabe destacar que, la tiroides secreta dos hormonas importantes, $\mathrm{T}_{4}$ y $\mathrm{T}_{3}$, tiroxina y triyodotironina, respectivamente. Su secreción la controla la tirotropina (TSH), la cual secreta la adenohipófisis. Estas actúan sobre múltiples tejidos y son esenciales para el desarrollo normal, el crecimiento y metabolismo. Una ausencia o secreción excesiva produce alteraciones en el metabolismo importantes. Por lo tanto, está formada por acinis glandulares o folículos, los cuales son irrigados por una red capilar muy rica; la pared del folículo está compuesta por una sola hilera de células epiteliales cuboidales, las cuales reposan sobre una membrana basal compuesta pormucopolisacáridos; el interior del folículo está lleno de un líquido claro y proteinàceo, llamado coloide acinar, el cual constituye la mayor parte de la masa tiroidea.

En consecuencia, el coloide contiene tiroglobulina, una proteína grande que pesa aproximadamente $650.000 \mathrm{MW}$, la cual sirve de transporte y bodega de las hormonas tiroideas durante su síntesis y al final de esta; la tiroglobulina es TSH- dependiente. Entre 20 y 40 de estos folículos forman un 
lobulillo, irrigado por sangre arterial y separada de los demás lobulillos por tejido conectivo. Entre los folículos se encuentran importantes células endocrinas pertenecientes al sistema APUD, denominadas células $\mathrm{C}$ o parafoliculares, que producen calcitonina, una hormona calciorreguladora. La irrigación de la tiroides está hecha por las arterias tiroideas superior e inferior; es excepcionalmente bien vascularizada, teniendo un flujo sanguíneo que varía entre 4 y $6 \mathrm{ml}$ por gramo de tejido tiroideo y por minuto, el cual es casi el doble del flujo renal. Esto tiene importancia fisiológica en lo que respecta a la capacidad para concentrar yodo

De este modo, se logra llevar a cabo el respectivo proceso de regulación fisiológica que no es más que un mecanismo de retroalimentación negativo hace que niveles aumentados de T4 libre (transformados en hipófisis e hipotálamo a T3), frenen la producción de TSH y también de la TRH u hormona liberadora de la tirotrofina, donde interviene otros órganos importantes del cuerpo humano como hipotálamo, hipófisis y la tiroides su combinación hace posible que los individuos puedan cumplir con la respectiva regulación fisiológica en cuanto a las hormas encargadas de producir por la referida glándula, a continuación se presenta la figura $\mathrm{n}^{\circ} 1$ que busca indicar la presencia del respectivo eje como medio fundamental para el bienestar integral de los individuos.

Figura $N^{\circ} 1$ Regulación Fisiológica de las Hormonas Tiroideas

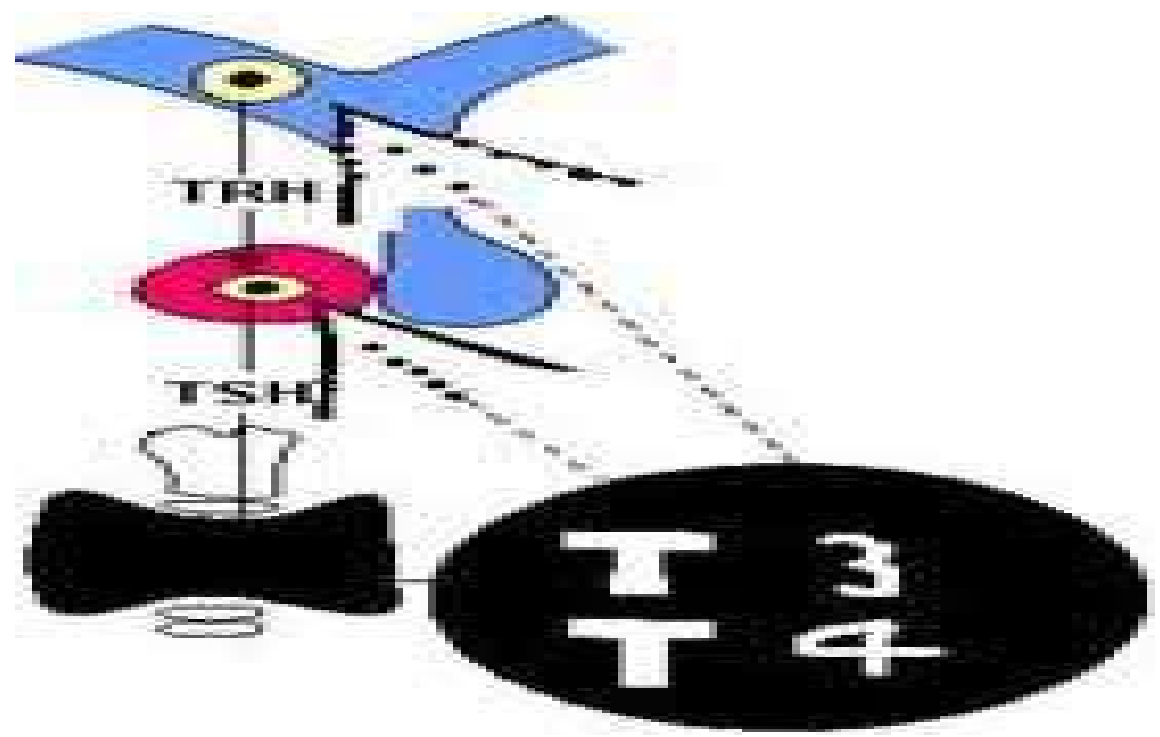

Fuente: $\operatorname{Paz}(2015)$ 
En relación al primer mecanismo resulta más importante pero un aumento de la TRH (que viaja por el sistema porta venoso del tallo hipofisiario) estimula la producción, tanto de la TSH como de la Prolactina. La TSH se fija a receptores localizados en las células epiteliales tiroideas, de esta manera favoreciendo la síntesis de la bomba de sodio o transportadora de yoduro, la peroxidasa tiroidea y la tiroglobulina; el aumento de la endocitosis epitelial tiroidea por la tirotropina también aumenta la liberación de hormona tiroidea en la circulación.

De acuerdo con la existencia de la regulación fisiológica se puede entender que la formación de hormonas tiroideas depende de un suministro adecuado de yodo; aunque hay mecanismos que garantizan la extracción máxima de yodo de la sangre para efectos de la tiroxinogènesis, en caso de deficiencias de yodo de larga data, estos pueden fallar. El balance de yodo es mantenido por la ingesta de este halógeno que viene en los alimentos y agua, pero especialmente en la sal yodada; otra fuente es la administración de medicamentos o medios de contraste yodados. En países como los Estados Unidos, la dieta corriente contiene unos 500 microgramos diarios, mientras que en Japón, esta cantidad es más alta y en otras regiones más baja.

\section{Cuadro $\mathbf{N}^{\circ} 1$ Hormonas Producidas por la Tiroides}

T abla I

\begin{tabular}{lcc}
\hline Hormonas & Hipertiroideo & Hipotiroideo \\
\hline Titoxina libre (T4L) & $\uparrow$ onomal & $\downarrow$ o nomal \\
Tri-yodo-Tirosina libre (T3L) & $\uparrow$ & \\
Tiroestimulina Hipofisaria Ultrasensible (TSH-US) & $\downarrow \downarrow \downarrow$ & $\uparrow \uparrow \uparrow$ \\
\hline Autoanticuerpos & BASEDOW & HASHIMOTO \\
\hline
\end{tabular}

TPO: autoanticuerpos anti-peloxiclasa. TR: A utoanticuerpos antieceptor cle la TSH: TG: autoanticuerpos antitiroglobulina.

Fuente: Paz (ob.cit)

Por lo tanto, la distribución de yodo en el organismo varía de acuerdo con el espacio o tejido en que se encuentra. Así, después de la transformación del elemento yodo en el Ion yoduro, en el intestino delgado se produce su absorción (unos $500 \mathrm{mcg}$ diarios); la mitad pasa al líquido extracelular. Hay una remoción constante del yoduro plasmático, que ingresa o reingresa al tiroides en un $20 \%$ 
(diariamente capta 120 y devuelve $60 \mathrm{mcg}$, el cual se origina de la dehalogenaciòn de las tirosinas). Un $77 \%$ se elimina por la orina (un promedio de $488 \mathrm{mcg}$ diarios) -aunque una buena cantidad se reabsorbe pasivamente por los túbulos renales- y un 3\% (12 mcg) por las heces. El total de hormona tiroidea en sangre (particularmente tiroxina), contiene $600 \mathrm{mcg}$ de yodo. $8 \mathrm{mg}$ del halógeno se encuentran en la glándula, el sitio de mayor concentración. Esta es misma cantidad se encuentra en una gota de solución de Lugol, mientras que otra de solución saturada de yoduro potásico contiene $50 \mathrm{mg}$.

Las consideraciones anteriores, permiten destacar que el proceso de regulación presente en la glándula tiroides, al cumplirse de manera funcional a sus características, hace posible mantener en el cuerpo humano niveles óptimos de tiroxina, pero cuando, se producen cambios en sus niveles bien sean bajos o altos se agrega una patología que va a estar caracterizada por la presencia de cambios en el organismo y en consecuencia el niño, niña, adolescente, adulto, embarazada o anciano que padezca la enfermedad debe ser tratado por los especialistas correspondientes a fin de darle el respectivo tratamiento y reducir las consecuencias presente.

\section{Patologías de la Tiroides}

Con el fin de comprender el significado de las patología, se puede indicar que la misma es una parte de la medicina que estudia los trastornos anatómicos y fisiológicos de los tejidos y órganos enfermos, así como los síntomas y signos a través de los cuales se manifiestan las enfermedades y las causas que las producen. En este sentido, se puede resaltar en cuanto a la glándula de la tiroides presenta una gama de patologías caracterizadas por Lares (2014) entre las cuales se encuentran las siguientes: "el bocio, hipertiroidismo, hipotiroidismo, orbitopatíatiroidea, nódulos tiroideos, cáncer de tiroides"(p.12). Las mismas se describen a continuación:

Bocio: Es un agrandamiento anormal de la glándula tiroides. La tiroides es una glándula con forma de mariposa que se encuentra en la base del cuello, abajo de la nuez de Adán. A pesar de que el bocio no suele ser doloroso, un bocio grande puede provocar tos y dificultades para tragar o respirar. El proceso comienza cuando el hipotálamo, una zona en la base del cerebro que actúa como termostato para todo el sistema, le indica a la hipófisis que fabrique una hormona conocida como tirotropina. La hipófisis, ubicada también en la base del cerebro, libera una determinada cantidad de tirotropina, dependiendo de la cantidad de tiroxina y T-3 que tengas en la sangre. La glándula 
tiroides, a su vez, regula su producción de hormonas según la cantidad de tirotropinaque reciba de la hipófisis.Tener bocio no necesariamente implica que la glándula tiroides no está funcionando normalmente. Incluso cuando está agrandada, la tiroides puede producir cantidades normales de hormonas. Sin embargo, podría ser que produzca una cantidad excesiva o muy pequeña de tiroxina y $\mathrm{T}-3$.

Hipotiroidismo: es el trastorno más común de la glándula tiroides. Es una situación clínica caracterizada por déficit de producción de hormonas tiroideas. Se clasifica en Hipotiroidismo primario: cuando la alteración se encuentra en la glándula tiroides. Hipotiroidismo secundario: cuando la alteración ocurre en la glándula hipófisis o en el hipotálamo. Por otro lado, el hipotiroidismo sub-clinico es una enfermedad asintomática en la mayoría de los casos, en la que la reducción del funcionamiento de la tiroides no es tanto como para que aparezcan signos clínicos. De acuerdo a la causa que originó el trastorno, el hipotiroidismo puede ser: Por deficiencia de yodo. En áreas del mundo con deficiencia de yodo en ladieta, tal como sucede en algunas áreas de México en las que puede ocurrirhipotiroidismo severo en 5\%-15\% de la población. Por este motivo suele añadirse yodo a la sal de mesa.Hipotiroidismo idiopático. En el que se desconoce la causa de la enfermedad Hipotiroidismo postablativo. Posterior a la extirpación quirúrgica de laglándula tiroides o después de la terapia con yodo radioactivo. Tiroiditis. Inflamación de la glándula tiroides producida por fenómenos autoinmunes, que se llama tiroiditis linfocítica crónica o tiroiditis de Hashimoto. Defectos en el desarrollo de la glándula tiroides. Son causa común en los primeros meses de vida.

Nódulos Tiroideos: La prevalencia estimada en la población general es cerca del $4.2 \%$, con una tasamucho más alta en las áreas con deficiencia de yodo. La mayoría de los nódulos sonparcialmente quísticos con un componente sólido, los nódulos puramente quísticosrepresentan cerca del 1\% de todos los nódulos. El cáncer de tiroides tiene una tasa hombre mujer de 1 a 2.5. El $74 \%$ de los nuevosdiagnósticos son mujeres y el cáncer de tiroides es el octavo cáncer más comúndiagnosticado en mujeres. La prevalencia incrementa con la edad, el riesgo de malignidad es mucho mayor enhombres. La exposición a radiación de la cabeza y el cuello en edades tempranaspredispone a que el 10 al $40 \%$ de aquellas personas desarrolle nódulos tiroideos enlos próximos 5 a 30 años. La exposición a radiaciones ionizantes causa que losnódulos se desarrollen a una tasa del $2 \%$ anual. 
Cáncer de Tiroides: El carcinoma de tiroides es la neoplasia maligna más frecuente del sistemaendocrino, se clasifican en base a sus características histológicas, asíel cáncer papilar de tiroides, el cáncer folicular del tiroides (los cuales son a menudo curables) y el cáncer anaplasico de tiroides (el cual tiene mal pronóstico).El cáncer papilar y el cáncer folicular son el cáncer de tiroides más frecuentes, conuna tasa de supervivencia a los 10 años del 98\% para el cáncer papilar, del 92\% parael cáncer folicular y del 13\% para el cáncer anaplasicoEl cáncer de tiroides tiene peor pronóstico en sujetos jóvenes (menor de 20 años) oen ancianos (mayor de 65 años), es dos veces más frecuente en las mujeres que loshombres pero tiene peor pronóstico en el sexo masculino. Factores de riesgoadicionales son la exposición previa a irradiación, nódulo de tamaño grande (mayor oigual a $4 \mathrm{~cm}$ ), signos de fijación local del tumor o de invasión de los ganglioslinfáticos.

Hipertiroidismo: Se conoce como tiroides hiperactiva. Ocurre cuando la glándula tiroides produce y libera demasiada hormona tiroidea. La glándula tiroides tiene forma de mariposa. Está ubicada en la parte delantera de su cuello, debajo de su nuez. La tiroides produce hormonas que controlan la forma en que su cuerpo usa la energía. Afecta su ritmo cardíaco y la función de sus otros órganos. También afecta sus músculos, huesos y ciclos menstruales (en el caso de las mujeres). En más del $70 \%$ de los casos, el hipertiroidismo es causado por la enfermedad de Graves. Normalmente, el sistema inmunitario ayuda a proteger su cuerpo contra virus, bacterias y otras sustancias. Una enfermedad autoinmune lo hace atacar los tejidos y/u órganos de su cuerpo. Con la enfermedad de Graves, el sistema inmunitario estimula la tiroides y hace que produzca demasiada hormona. Los médicos piensan que la enfermedad de Graves puede ser hereditaria. Es más común entre las mujeres jóvenes.

OrbitopatíaTiroidea: Es una enfermedad debilitante del sistema visual, caracterizada por presentar cambios de los tejidos blandos orbitarios y periorbitarios debidos a un proceso inflamatorio, se relaciona con alteraciones endocrinas sistémicas de la glándula tiroides, causando una alteración significativa en la calidad de vida de los afectados. La orbitopatia tiroidea (OT) es la primera causa de patología orbitaria, con una incidencia que oscila entre el 50 y $60 \%$ en la consulta de un cirujano de órbita. Es conocida también con el nombre de oftalmopatia de Graves por su asociación con la enfermedad de Graves, considerándose la manifestación extratiroidea más frecuente de esta enfermedad, aunque puede presentarse en pacientes sin historia pasada o presente de hipertiroidismo (eutiroideos), en pacientes hipotiroideos y en la tiroiditis de Hashimoto. 
Figura $\mathbf{N}^{\circ} 2$. Orbitopatía Tiroidea

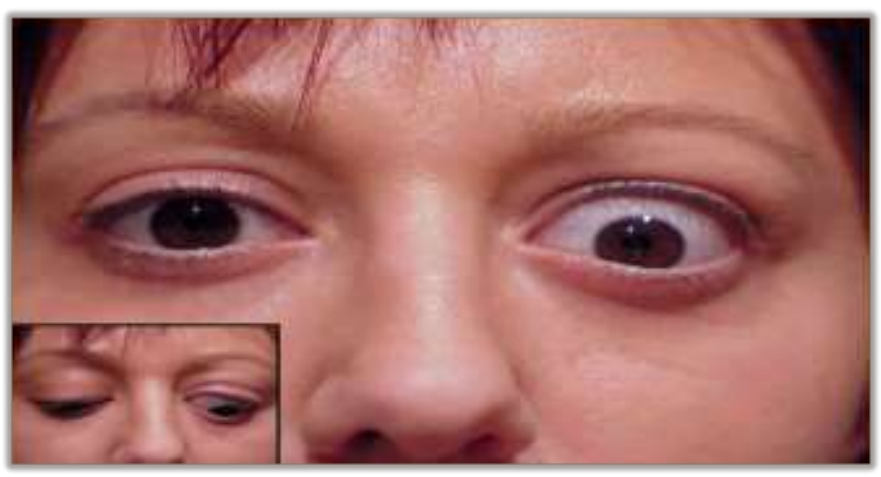

Fuente: Elaboración Propia (2019).

Es importante acotar que, está patología produce un engrosamiento de las glándulas lagrimales, las cuales se hacen palpables en su región palpebral, no siendo infrecuente que durante las blefaroplastias superiores para la rehabilitación quirúrgica de estos pacientes nos encontremos con una ptosis o hernia glandular la cual tengamos que reparar y recolocar la misma en su posición original sujetada al arcusmarginalis. La glándula aparece móvil, de consistencia firme y no dolorosa a la presión. La infiltración celular de la glándula lagrimal, puede en algunos casos, producir destrucción de los acinos con fibrosis y disminución de la secreción lagrimal, lo que puede llevar a un empeoramiento de las alteraciones de la superficie ocular, cursando en primer lugar con epifora y posteriormente evolucionar hacia un síndrome de ojo seco.

\section{Conclusiones.}

En función a cada uno de los planteamientos citados a lo largo del desarrollo de este artículo, se pueden concluir lo siguiente:

Las hormonas tiroideas desempeñan un papel fundamental en el crecimiento somático y regulan numerosos procesos metabólicos. La síntesis de hormonas tiroideas requiere una glándula tiroidea desarrollada normalmente, un aporte nutricional de yodo adecuado y una serie de reacciones bioquímicas secuenciales complejas, procesos controlados por el sistema regulador hipotálamohipofisario y por la propia autorregulación tiroidea. Las numerosas funciones ejercidas por las hormonas tiroideas en prácticamente todos los tejidos del organismo se producen a través de su 
interacción con diferentes receptores, proteínas correguladoras y otras proteínas asociadas a receptores nucleares.

En cuanto a la patología vinculada con los ojos, se muestra un cambio pupilar que afecta a las personas para realizar sus actividades diarias, además agrega otras situaciones vinculadas con el ojo seco. Es importante indicar, que cada una de las enfermedades generadas por una inadecuado funcionamiento de la tiroides lleva a la manifestación de diferentes síntomas; también se precisa que su diagnóstico temprano le confiere al paciente la posibilidad de tener una mejor calidad de vida. Pues, el tratamiento con yodo hace posible mantener una regulación fisiológica de la glándula de forma significativa.

Cabe agregar que las ciencias médicas en la actualidad en cuanto a la etiología del hipotiroidismo subclínico no está aclarada, aunque se señalan múltiples trastornos relacionados con el riesgo de padecer esta condición, entre los que se considera: disfunción tiroidea previa, bocio asociado a trastornos autoinmunes o con deficiencia de yodo, poscirugía o radioterapia sobre la glándula tiroides, enfermedades autoinmunes no tiroideas como la diabetes mellitus tipo 1, el vitiligo, la anemia perniciosa, la anemia hemolítica autoinmune, la canicie precoz, el envejecimiento y el consumo de medicamentos (litio, amiodarona, antitiroideos de síntesis, radioyodo, expectorantes que contienen yoduro de potasio y otros). En los antecedentes familiares de estos pacientes se recogen la enfermedad tiroidea, la anemia perniciosa, la diabetes mellitus tipo 1 y la insuficiencia suprarrenal primaria

Según la literatura revisada se puede decir que, el yodo, es esencial para la producción de hormonas tiroideas, se encuentra principalmente en el agua de mar y en el suelo de las zonas costeras. En los países en vías de desarrollo, las personas que viven en el interior o en zonas elevadas, a menudo, tienen deficiencias de yodo y pueden padecer bocio cuando la tiroides se agranda, en un esfuerzo por obtener más yodo. La deficiencia inicial de yodo puede empeorar aún más si la persona lleva una dieta alta en alimentos inhibidores de la hormona tiroidea, como repollo, brócoli y coliflor. Si bien la falta de yodo en la dieta es la principal causa de bocio en muchas partes del mundo, a menudo este no es el caso en países en los que se agrega yodo de manera rutinaria a la sal de mesa y a otros alimentos. 
Marcos A. Bedoya-Romo; Pierina E. Saltos-Montes; Marcos A. Campozano-Burgos; Eduardo I. Ayala-Morillo; Evelyn E. Calderón-López; Marvin D. Veliz-Mero

\section{Bibliografia.}

Barrero, V. (2018). Proyectos de Trabajo Científico. Valencia: Greco.

Barrientos, D. (2019). Cáncer de Tiroides. New York: Hill Americana.

Carrero, D. (2017). Metología de Investigación . España: Gedisa.

Hernández, M. y. (2015). Fisiología de las Glándulas Tiroides y Paratiroides. En F. Bueno, Laringe y Patología (pág. 7). México: Mac Graw Hill.

Instituto Ecuatoriano de Estadísticas y Censos INEC. (8 de Abril de 2017). Obtenido de https:/www.redacionmedica.ec/...carsinoma-de-tiroides-el-m-s-com-n-entre las -mujeres:

Lares, O. (2014). Enfermedades Tiroideas . La Habana: Mundo Cultural .

Paz, B. (2015). Glándula Tiroides. Regulación de Hormonas. España: Santillana.

Salazar, R. (2016). Actualización Patológica Tirodea . España: Morata.

Salud, O. M. (8 de Abril de 2016). https://www.thyroid.org/deficienciade-yod/. Obtenido de https://www.thyroid.org/deficienciade-yod/ 